\title{
O processo de trabalho na Estratégia Saúde da Família e suas repercussões no processo saúde-doença
}

\author{
The working process in the Family Health Strategy \\ and its repercussions on the health-disease process
}

Helena Eri Shimizu ${ }^{1}$

Daniel Alvão de Carvalho Junior ${ }^{1}$

${ }^{1}$ Departamento de

Enfermagem, Faculdade de Ciências da Saúde, Universidade de Brasília. Campus Universitário Darcy Ribeiro S/N, Asa Norte. 70910-900 Brasília DF.shimizu@unb.br

\begin{abstract}
This study analyzes the perceptions that health workers engaged in the Family Heath Strategy (FHS) of the Federal District (FD) have of their own work process and its repercussions on the health-illness process. It is a cross-sectional descriptive survey carried out with a sample of 243 FHS/FD workers: 139 community health agents, 47 nursing assistants, 41 nurses, and 11 doctors. Four previously validated scales were used (Evaluation of Work Context, Human Cost at Work, Pain and Pleasure, Work Inventory and Risk of illness). The results revealed a highly Taylorised type of work process management typified by a sharp work distinction between formulators and performers, highly repetitive work tasks, performance supervision and very weak formal communication between the various hierarchical levels. These factors have seriously impaired the reregulation of the work process by confronting current objective and subjective realities with preexisting norms. In conclusion, the Taylorised work processes, the precarious working conditions and the specific difficulties associated with providing care to families and communities in their own territories are highly stressful and debilitating and underscore the need for improved management of the respective work processes.
\end{abstract}

Key words Family Health, Occupational health, Primary Healthcare
Resumo Este estudo analisa a percepção dos trabalhadores da Estratégia Saúde da Família do Distrito Federal (ESF-DF) acerca de seu processo de trabalho e suas repercussões no processo saúdedoença. Pesquisa descritivo-transversal realizada com 243 trabalhadores da ESF-DF, sendo 139 agentes comunitários de saúde, 47 auxiliares de enfermagem, 41 enfermeiros e 11 médicos. Foram utilizadas quatro escalas (Avaliação do Contexto de Trabalho; Custo Humano no Trabalho; Sofrimento e Prazer, do Inventário de Trabalho e Riscos de Adoecimento), validadas previamente. Evidenciase um modo de gestão do processo de trabalho taylorizado, caracterizado pela divisão de trabalho entre formuladores e executores, pela repetição das tarefas, pela fiscalização de desempenho e pela fragilidade da comunicação formal entre os diferentes níveis hierárquicos. Esses fatores têm dificultado o processo de renormatização do processo de trabalho, por meio da confrontação das normas preexistentes e a realidade objetiva e subjetiva. Conclui-se que o processo de trabalho taylorizado, as precárias condições de trabalho e as exigências específicas dos cuidados das famílias e das comunidades em seu território provocam desgastes intensos, que apontam a necessidade de aprimoramento da sua gestão.

Palavras-chave Saúde da família, Saúde do trabalhador, Atenção primária à saúde 


\section{Introdução}

A Atenção Primária à Saúde (APS) é considerada o modelo de gestão de sistema mais adequado para lidar com o aumento da longevidade populacional, que tem como um de seus pilares a reorganização do processo de trabalho dos profissionais de saúde e inovações no relacionamento destes com a população $0^{1-3}$.

Na Estratégia Saúde da Família (ESF), considerada a principal estratégia para o reordenamento da APS, atualmente denominada de Atenção Básica $(\mathrm{AB})$, propõe-se ultrapassar o modelo de atenção baseado na biomedicina, que tradicionalmente tem como objeto do trabalho, em saúde, o corpo. Este é socialmente estruturado, codificado e dividido em partes específicas, em que o que se busca são anomalias estruturais ou funcionais, materializadas no tecido biológico.

Busca-se por um modelo de atenção integral à saúde, no qual o objeto de intervenção seja mediado pela família, pela comunidade onde está inserido ${ }^{1,4,5}$. A eficácia na ESF supõe o trabalho em equipe e a interação organizada entre indivíduos com competências e habilidades distintas.

Essa dinâmica proporciona possibilidades de cuidados mais completos, mas também aumenta as competições entre os profissionais, bem como as diferenças entre as prescrições e o trabalho real, que tornam mais complexas as interações entre os indivíduos, entre estes e seu objeto de trabalho, e as resultantes de todos esses encontros ${ }^{4,6,7}$.

Além disso, dentre os diversos modelos de gestão do processo de trabalho, deparamo-nos na APS com o modelo taylorista - baseado na divisão entre executores e planejadores, na normatização de processos e procedimentos, e na não cooperação entre indivíduos e especialidades - ainda predominar ${ }^{2,3,8,9}$.

Nessa perspectiva, destaca-se a relevância de permitir o controle do processo de trabalho pelos indivíduos e pelos coletivos ${ }^{10}$. Controle no sentindo de poder construir suas próprias normas, subvertendo as vigentes na prática da atividade. Este poder, esta potência, relaciona-se diretamente com o processo saúde-doença do ser humano:

Nesse sentido, Dejours ${ }^{11-13}$ e Schwartz ${ }^{14-16}$ apontam que a forma concreta de organização do trabalho influencia o estado de saúde dos trabalhadores, ao propiciar ou dificultar os mecanismos de reelaboração das normas, consequentemente do sofrimento vivenciado por eles.

Comumente as organizações hierarquicamente rígidas ${ }^{17}$ tendem a potencializar o sofri- mento de seus membros, pois desconsideram as limitações de seus modelos e normas prescritivos, bem como não reconhecem as iniciativas de adaptação de seus membros hierarquicamente inferiores. Todavia, essa mesma conformação, a divisão rígida e inflexível do trabalho reduzem as incertezas dos trabalhadores de todos os níveis da organização, permitindo a quantificação, a simplificação e o controle ${ }^{11,13}$.

As organizações que se baseiam na polivalência, em conhecimentos e práticas generalistas como ocorre na ESF aumentam as incertezas de seus membros, que por sua vez, aumentam a tensão no trabalho, tornando mais complexo o processo de coordenação do processo de trabalho ${ }^{13,17,18}$.

Portanto, no âmbito da gestão do trabalho em saúde, é relevante analisar, além do contexto, a dinâmica do processo de trabalho, a experiência subjetiva, os valores tomados em consideração nas decisões durante o curso da atividade, assim como os desgastes e prazeres.

Este estudo tem como objetivo geral analisar a percepção dos trabalhadores da equipe básica da ESF-DF acerca do processo de trabalho e suas repercussões no processo saúde-doença, a fim de oferecer subsídios para se repensar a gestão. E como objetivos específicos: avaliar o contexto de trabalho, entendido por condições, organização e relações socioprofissionais; o custo humano, que envolve o físico, o cognitivo e o afetivo; e as vivências de sofrimento-prazer no trabalho, constituído por realização profissional, liberdade de expressão, esgotamento profissional e falta de reconhecimento profissional.

\section{Método}

Trata-se de uma pesquisa descritiva, transversal $^{19}$, realizada com 243 trabalhadores que constituem as equipes básicas da ESF no Distrito Federal, sendo 139 agentes comunitários de saúde, 47 auxiliares de enfermagem, 41 enfermeiros e 11 médicos.

Para a coleta de dados, foi utilizado um instrumento denominado Inventário sobre Trabalho e Risco de Adoecimento (ITRA), que possibilita a estruturação de diagnósticos de indicadores críticos relacionados ao trabalho, validada previamente $^{20}$.

O ITRA é composto por quatro distintas escalas $^{20}$, entretanto foram utilizadas apenas a Escala de Avaliação do Contexto do Trabalho (EACT), que analisa fatores relacionados à organização do trabalho, às relações socioprofissi- 
onais e às condições de trabalho, a Escala de Custos Humanos do Trabalho (ECHT), que avalia os custos relacionados aos aspectos físico, cognitivo e afetivo, e Escala de Indicadores de Prazer-Sofrimento no Trabalho (EIPST), que analisa os fatores realização profissional, liberdade de expressão, esgotamento e falta de reconhecimento no trabalho.

São escalas do tipo Likert de 5 pontos que se referem à frequência de ocorrência de determinados fenômenos, em que o valor 1 indica nunca, 2 = raramente, $3=$ às vezes, $4=$ frequentemente e $5=$ sempre $^{20}$.

Para avaliação dos fatores relativos ao contexto de trabalho e custos humanos, obedecemse aos seguintes valores, acima de 3,7 (grave), entre 2,3 e 3,69 (crítica) e abaixo de 2,29 (satisfatória $)^{20}$. Para avaliação do prazer, seguem-se os parâmetros: maior ou igual a 4,0 = satisfatória; de 2,1 a 3,9 = crítica; menor ou igual a 2,0 = grave. E para avaliação do fator sofrimento, utilizam-se os parâmetros invertidos: menor ou igual a 2,0 = satisfatória; de 2,1 a 3,9 = crítica; maior ou igual a $4,0=$ grave $^{20}$.

A realização da pesquisa foi autorizada pelo Comitê de Ética em Pesquisa da SES-DF. Todos os participantes assinaram o Termo Consentimento Livre e Esclarecido, conforme a resolução 196/96 do Conselho Nacional de Saúde ${ }^{21}$.

\section{Resultados}

Pelos dados obtidos relativos ao contexto de trabalho, no que se refere à organização do trabalho, demonstrados na Tabela 1 , foi avaliada positivamente a existência de tempo para realizar pausas de descanso durante o trabalho (média 2,56 e mediana 2,5). Avaliaram-se, porém, como críticos, a divisão de trabalho entre planejadores e executores (média 3,32 e mediana 3), o ritmo de trabalho (média 2,85 mediana 3 ), a pressão, em termos de prazos para a realização do trabalho (média 3,01 e mediana 3), a cobrança por resultados (média 3,01 e mediana 3 ) e a falta de pessoal para a realização das tarefas (média 3,2 e mediana 3), caracterizadas como estratégias de gestão voltadas para o aumento da produtividade.

Existem problemas na gestão do processo de trabalho, e também foram avaliadas como críticas a rigidez das normas para a execução das tarefas (média 2,78 e mediana 3), a descontinuidade na execução destas (média 2,98 e mediana 3), a fiscalização de desempenho no trabalho (média 3,47 e mediana 3) e os resultados fora do esperado (média 2,8 e mediana 3). Destarte, a repetição de tarefas foi avaliada como grave (média 4,05 e mediana 4).

As condições de trabalho foram avaliadas como críticas (média 3,53 e mediana 3), no que se refere ao desconforto do ambiente físico (média 3,35 e mediana 3), à existência de barulho no ambiente de trabalho (média 3,15 e mediana 3), à inadequação do mobiliário existente (média 3,43 e mediana 3), à inadequação do posto de trabalho para a realização das tarefas (média 3,27 e mediana 3) e falta à de segurança das pessoas (média 3,14 e mediana 3). E foram avaliadas como muito graves a insuficiência de instrumentos (média 3,75 e mediana 4), a precariedade dos equipamentos existentes (média 3,65 e mediana 4), a inadequação do espaço físico (média 3,62 e mediana 4) e a insuficiência de material de consumo (média 3,79 e mediana 4).

Foram avaliadas como graves as relações socioprofissionais, como a dificuldade na comunicação entre chefia e subordinados (média 3,75 e mediana 4), a falta de integração no ambiente de trabalho (média 3,65 e mediana 4), a comunicação entre os funcionários (média 3,62 e mediana 4), além da falta de apoio das chefias para o desenvolvimento profissional (média 3,79 e mediana 4).

Verificou-se também que foram avaliados como críticos os aspectos relacionados à forma de relacionamento da gestão com as equipes de trabalho: a falta de clareza na definição das tarefas (média 3,53 e mediana 3), a inexistência de autonomia (média 3,35 e mediana 3 ), a injustiça na distribuição de tarefas (média 3,15 e mediana 3), a exclusão do processo decisório (média 3,43 e mediana 3), a existência de disputas no local de trabalho (média 3,27 e mediana 3) e dificuldade de acesso às informações necessárias à execução do trabalho (média 3,18 e mediana 3).

Os resultados da ECHT, apresentados na Tabela 2, mostram que foram positivamente avaliados os itens relacionados ao uso de força física (média 2,2 e mediana 2), manuseio de objetos pesados (média 1,95 e mediana 2) e ao ato de subir e descer escadas (média 1,68 e mediana 1), ou seja, são eventos que ocorrem com frequência considerada satisfatória, não provocando desgaste.

Os itens relacionados a usar os braços de forma contínua (média 3,11 e mediana 3 ), ficar em posição curvada (média 2,52 e mediana 3 ), ser obrigado a ficar em pé (média 3,15 e mediana 3) e a fazer esforço físico (média 2,83 e mediana 3) foram avaliados como estando em situação crítica. Foram avaliados como situação grave, de- 
Tabela 1. Avaliação do contexto de trabalho pelos trabalhadores da ESF-DF, 2010

\begin{tabular}{|c|c|c|c|}
\hline & Média & Mediana & $\begin{array}{l}\text { Desvio } \\
\text { padrão }\end{array}$ \\
\hline \multicolumn{4}{|l|}{ Itens: Organização do trabalho } \\
\hline 1. Falta tempo para realizar pausas de descanso no trabalho & 2,56 & 2,5 & 1,20 \\
\hline 2. Ritmo do trabalho é excessivo & 2,85 & 3 & 0,86 \\
\hline 3. Tarefas são cumpridas sob pressão de prazos & 3,01 & 3 & 1,06 \\
\hline 4. Existe forte cobrança por resultados & 3,34 & 3 & 1,13 \\
\hline 5. As normas para execução das tarefas são rígidas & 2,78 & 3 & 1,15 \\
\hline 6. Existe fiscalização do desempenho & 3,47 & 3 & 1,16 \\
\hline 7. O número de pessoas é insuficiente para realizar as tarefas & 3,2 & 3 & 1,43 \\
\hline 8. Os resultados esperados estão fora da realidade & 2,80 & 3 & 1,24 \\
\hline 9. Existe divisão entre quem planeja e quem executa & 3,32 & 3 & 1,34 \\
\hline 10. As tarefas executadas sofrem descontinuidade & 2,98 & 3 & 1,19 \\
\hline 11. As tarefas são repetitivas & 4,05 & 4 & 0,96 \\
\hline \multicolumn{4}{|l|}{ Itens: Condições de trabalho } \\
\hline 12. As condições de trabalho são precárias & 3,53 & 3 & 1,31 \\
\hline 13. O ambiente físico é desconfortável & 3,35 & 3 & 1,31 \\
\hline 14. Existe muito barulho no ambiente de trabalho & 3,15 & 3 & 1,22 \\
\hline 15. O mobiliário existente no local de trabalho é inadequado & 3,43 & 3 & 1,27 \\
\hline 16. O posto de trabalho é inadequado para a realização das tarefas & 3,27 & 3 & 1,29 \\
\hline 17. As condições de trabalho oferecem riscos à segurança das pessoas & 3,14 & 3 & 1,28 \\
\hline 18. Os instrumentos de trabalho são insuficientes para realizar as tarefas & 3,75 & 4 & 1,02 \\
\hline 19. Os equipamentos necessários para realização das tarefas são precários & 3,65 & 4 & 1,02 \\
\hline 20. O espaço físico para realizar o trabalho é inadequado & 3,62 & 4 & 1,26 \\
\hline 21. O material de consumo é insuficiente & 3,79 & 4 & 1,08 \\
\hline \multicolumn{4}{|l|}{ Itens: Relações socioprofissionais } \\
\hline 22. As tarefas são claramente definidas & 3,53 & 3 & 1,31 \\
\hline 23. A autonomia é inexistente & 3,35 & 3 & 1,31 \\
\hline 24. A distribuição das tarefas é injusta & 3,15 & 3 & 1,22 \\
\hline 25. Os funcionários são excluídos das decisões & 3,43 & 3 & 1,27 \\
\hline 26. Existem disputas profissionais no local de trabalho & 3,27 & 3 & 1,28 \\
\hline 27. As informações que preciso para executar minhas tarefas são de difícil acesso & 3,18 & 3 & 1,18 \\
\hline 28. Existem dificuldades na comunicação entre chefia e subordinados & 3,75 & 4 & 1,02 \\
\hline 29. Falta integração no ambiente de trabalho & 3,65 & 4 & 1,02 \\
\hline 30. A comunicação entre os funcionários é insatisfatória & 3,62 & 4 & 1,26 \\
\hline 31. Falta apoio das chefias para o meu desenvolvimento profissional & 3,79 & 4 & 1,08 \\
\hline
\end{tabular}

notando desgaste físico intenso, os atos de caminhar (média 4,19 e mediana 4), de usar continuamente as pernas (média 3,94 e mediana 4) e as mãos (média 3,84 e mediana 4.

Em relação aos custos cognitivos, foram avaliados como críticos, o desenvolvimento de macetes (média 2,9 e mediana 3), a previsão de acontecimentos (média 3,31 e mediana 3 ) e a existência de desafios intelectuais (média 3,53 e mediana 3). E foram avaliados como graves os itens referentes à frequência com que problemas têm de ser resolvidos (média 3,92 e mediana 4), lidar com imprevistos (média 3,92 e mediana 4), utilizar a visão de forma contínua (média 4,13 e mediana 4), fazer esforço mental (média 3,84 e mediana 4), concentrar-se com frequência (média 3,97 e me- diana 4), usar a criatividade (média 4,13 e mediana 4) e a memória (média 4,40 e mediana 4).

Os custos afetivos foram considerados satisfatórios, denotando a não submissão a situações constrangedoras (média 2,33 e mediana 2) e que envolvam transgressões de valores éticos (média 1,97 e mediana 1). Os itens referentes a ter de lidar com ordens contraditórias (média 3,34 e mediana 3), à obrigatoriedade de cuidar da aparência física (média 3,22 e mediana 3), a ser bonzinho com outros (média 3,37 e mediana 3 ) e a ser obrigado a sorrir (média 2,51 e mediana 2) foram avaliados como críticos.

Foram avaliadas como situações graves: o ato de controlar as emoções (média 4,31 e mediana 4), ser obrigado a lidar com a agressividade alheia 
Tabela 2. Avaliação dos custos humanos do trabalho percebidos pelos trabalhadores da ESF-DF, 2010

\begin{tabular}{|c|c|c|c|}
\hline & Média & Mediana & Desvio padrão \\
\hline \multicolumn{4}{|l|}{ Itens: Custo físico } \\
\hline 1. Subir e descer escadas & 1,68 & 1 & 0,92 \\
\hline 2. Usar a força física & 2,2 & 2 & 1,08 \\
\hline 3. Ter que manusear objetos pesados & 1,95 & 2 & 0,96 \\
\hline 4. Usar os braços de forma contínua & 3,11 & 3 & 1,32 \\
\hline 5. Ficar em posição curvada & 2,52 & 3 & 1,22 \\
\hline 6. Ser obrigado a ficar em pé & 3,15 & 3 & 1,31 \\
\hline 7. Fazer esforço físico & 2,83 & 3 & 1,25 \\
\hline 8. Usar as pernas de forma contínua & 3,94 & 4 & 1,20 \\
\hline 9. Usar as mãos de forma repetida & 3,84 & 4 & 1,21 \\
\hline 10. Caminhar & 4,19 & 5 & 1,05 \\
\hline \multicolumn{4}{|l|}{ Itens: Custo cognitivo } \\
\hline 11. Desenvolver macetes & 2,9 & 3 & 1,09 \\
\hline 12. Fazer previsão de acontecimentos & 3,31 & 3 & 1,16 \\
\hline 13. Ter desafios intelectuais & 3,53 & 3 & 1,20 \\
\hline 14. Ter que resolver problemas & 3,92 & 4 & 0,96 \\
\hline 15. Ser obrigado a lidar com imprevistos & 3,92 & 4 & 0,99 \\
\hline 16. Usar a visão de forma contínua & 4,13 & 4 & 1,05 \\
\hline 17. Fazer esforço mental & 3,84 & 4 & 1,14 \\
\hline 18. Ter concentração mental & 3,97 & 4 & 1,02 \\
\hline 19. Usar a criatividade & 4,13 & 4 & 0,89 \\
\hline 20. Usar a memória & 4,40 & 5 & 0,79 \\
\hline \multicolumn{4}{|l|}{ Itens: Custo afetivo } \\
\hline 21. Transgredir valores éticos & 1,97 & 1 & 1,31 \\
\hline 22. Ser submetido a constrangimentos & 2,33 & 2 & 1,09 \\
\hline 23. Ser obrigado a sorrir & 2,51 & 2,5 & 1,37 \\
\hline 24. Ter que lidar com ordens contraditórias & 3,34 & 3 & 1,20 \\
\hline 25. Ser obrigado a cuidar da aparência física & 3,22 & 3 & 1,42 \\
\hline 26. Ser bonzinho com os outros & 3,37 & 3 & 1,28 \\
\hline 27. Ter controle das emoções & 4,31 & 4 & 0,78 \\
\hline 28. Ter custo emocional & 3,51 & 4 & 1,14 \\
\hline 29. Ser obrigado a lidar com a agressividade dos outros & 3,64 & 4 & 1,10 \\
\hline 30. Disfarçar os sentimentos & 3,57 & 4 & 1,12 \\
\hline 31. Ser obrigado a ter bom humor & 3,52 & 4 & 1,23 \\
\hline
\end{tabular}

(média 3,64 e mediana 4), disfarçar os sentimentos (média 3,57 e mediana 4), aparentar ter bom humor (média 3,52 e mediana 4) e ter custo emocional (média 3,51 e mediana 4).

A Tabela 3 apresenta os resultados obtidos com a aplicação da EIPST, evidenciando que os trabalhadores avaliam positivamente o trabalho, pois expressaram satisfação (média 4,47; mediana 5), orgulho pelo que fazem (média 4,75; mediana 6) e sensação de bem-estar (média 4,25 e mediana 5). Ocorre também a identificação com a tarefa que desenvolvem (média 4,25 e mediana 5), a sensação de gratificação pessoal (média 4,1 e mediana 5), a motivação (média 3,69 e mediana 4) e a percepção de realização profissional (média 3,68 e mediana 4).
No entanto, os itens referentes à valorização profissional (média 3,12; mediana 3 ) e ao reconhecimento (média 2,86; mediana 3 ) foram avaliados como críticos.

Os resultados evidenciam que há solidariedade entre os colegas (média 4,67; mediana 5) e confiança entre os trabalhadores (média 4,09 e mediana 5). Há liberdade para expressão de ideias no local de trabalho (média 4,35; mediana 5), para o uso da criatividade individual (média 4,64; mediana 5) e para falar sobre o trabalho com as chefias (média 4,5; mediana 5). Além disso, há cooperação entre os colegas (média 4,54; mediana 5), liberdade de negociação com a chefia (média 4,5; mediana 6), bem como para falar sobre o trabalho com os colegas (média 4,84; mediana 6). 


\begin{tabular}{|c|c|c|c|c|}
\hline \multirow{37}{*}{ 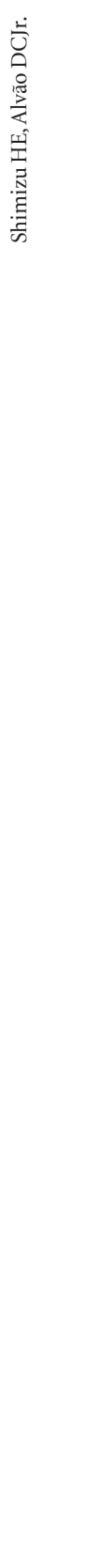 } & Tabela 3. Avaliação da vivência do prazer-sofrimento pelos trabalh & lores da $\mathrm{F}$ & SF-DF, 2010. & \\
\hline & & Média & Mediana & Desvio padrão \\
\hline & Itens: Realização profissional & & & \\
\hline & 1. Valorização & 3,12 & 3 & 2,13 \\
\hline & 2. Reconhecimento & 2,86 & 3 & 2,04 \\
\hline & 3. Motivação & 3,69 & 4 & 1,81 \\
\hline & 4. Realização profissional & 3,68 & 4 & 2,04 \\
\hline & 5. Satisfação & 4,47 & 5 & 1,65 \\
\hline & 6. Bem-estar & 4,25 & 5 & 1,74 \\
\hline & 7. Identificação com a própria tarefa & 4,21 & 5 & 1,90 \\
\hline & 8. Gratificação pessoal com as minhas atividades & 4,12 & 5 & 2,10 \\
\hline & 9. Orgulho pelo que faço & 4,75 & 6 & 1,77 \\
\hline & Itens: Liberdade de expressão & & & \\
\hline & 10. Solidariedade entre os colegas & 4,67 & 5 & 1,76 \\
\hline & 11. Confiança entre os colegas & 4,09 & 5 & 1,85 \\
\hline & 12. Liberdade para expressar minhas opiniões no local de trabalho & 4,35 & 5 & 1,97 \\
\hline & 13. Liberdade para usar a minha criatividade & 4,64 & 5 & 1,74 \\
\hline & 14. Liberdade para falar sobre o meu trabalho com as chefias & 4,5 & 5 & 1,97 \\
\hline & 15. Cooperação entre os colegas & 4,53 & 5 & 1,62 \\
\hline & 16. Liberdade com a chefia para negociar o que precisa & 4,50 & 6 & 2,03 \\
\hline & $\begin{array}{l}\text { 17. Liberdade para falar sobre o meu trabalho com os colegas } \\
\text { Itens: Esgotamento profissional }\end{array}$ & 4,84 & 6 & 1,75 \\
\hline & 18. Medo & 2,64 & 2 & 2,26 \\
\hline & 19. Esgotamento emocional & 3,32 & 3 & 2,09 \\
\hline & 20. Insatisfação & 3,00 & 3 & 2,01 \\
\hline & 21. Sobrecarga & 2,91 & 3 & 2,06 \\
\hline & 22. Frustração & 2,84 & 3 & 2,23 \\
\hline & 23. Insegurança & 3,05 & 3 & 2,18 \\
\hline & 24. Estresse & 3,46 & 4 & 2,18 \\
\hline & Itens: Falta de reconhecimento & & & \\
\hline & 25. Discriminação & 1,49 & 0 & 2,08 \\
\hline & 26. Inutilidade & 1,56 & 1 & 2,02 \\
\hline & 27. Desqualificação & 1,61 & 1 & 2,03 \\
\hline & 28. Injustiça & 2,09 & 1 & 2,17 \\
\hline & 29. Falta de reconhecimento do meu esforço & 2,56 & 2 & 2,14 \\
\hline & 30. Falta de reconhecimento do meu desempenho & 2,56 & 2 & 2,19 \\
\hline & 31. Desvalorização & 2,55 & 2 & 2,27 \\
\hline & 32. Indignação & 2,41 & 2 & 2,23 \\
\hline
\end{tabular}

Apesar da avaliação positiva do trabalho e das relações entre os integrantes da esquipe, as vivências de sofrimento no trabalho estão presentes. Os itens esgotamento emocional (média 3,32; mediana 3), insatisfação (média e mediana iguais a 3), sobrecarga (média 2,91; mediana 3), frustração (média 2,84; mediana 3 ) e insegurança (média 3,05 e mediana 3) são avaliados como situação crítica, contudo não ocorre a vivência de medo (média 2,64; mediana 2).

As situações de trabalho que provocam estresse nos trabalhadores são tão frequentes que os trabalhadores avaliam este item como grave (média 3,46 e mediana 4). Apesar disso, os itens relacionados foram avaliados como satisfatórios, ou seja, não ocorrem ou são escassas a percepção de discriminação (média 1,49; mediana 0 ), de sensação de inutilidade (média 1,56; mediana 1), de desqualificação (média 1,61; mediana 1), de injustiça (média 2,09; mediana 1), de desvalorização (média 2,55; mediana 2) e de indignação (média 2,41; mediana 2).

Além disso, os trabalhadores avaliam como suportáveis as vivencias de falta de reconhecimento pelo esforço realizado no cumprimento das atividades (média 2,56; mediana 2) e da falta de reconhecimento em relação ao desempenho individual (média 2,56; mediana 2). 


\section{Discussão}

Uma das limitações do estudo é o não aprofundamento da compreensão da dimensão subjetiva e intersubjetiva envolvidas na avaliação da relação entre processo de trabalho e processo saúdedoença. Uma segunda limitação é a possibilidade de viés de prevalência, própria do estudo de tipo transversal. Além disso, pode-se considerar a dificuldade da utilização de um instrumento validado previamente em outros tipos de trabalho.

No que se refere à avaliação do contexto de trabalho, com relação ao modo de organização do trabalho na ESF/DF, as tarefas foram consideradas muito repetitivas pela maioria dos trabalhadores. O ritmo de trabalho, a pressão - em termos de prazos para a realização do trabalho a cobrança por resultados e a falta de pessoal para a realização das tarefas, a fiscalização de desempenho no trabalho e os resultados desejados não condizentes com a realidade, foram considerados fatores críticos, o que revela um enfoque da gestão voltada para o incremento da produtividade.

No que concerne ao desempenho quotidiano do processo de trabalho, foram avaliadas também como críticas a rigidez das normas para a execução das tarefas, a divisão de trabalho entre planejadores e executores, a ocorrência de descontinuidade na execução das tarefas.

Esse conjunto de resultados indica a possibilidade de que o processo de trabalho na ESF/DF dê-se nos marcos do modelo difundido por Taylor e que se baseia, exatamente, na repetição, na divisão entre formuladores e executores, no estabelecimento de metas de produtividade e na dificuldade na comunicação entre os diferentes níveis hierárquicos, dentre outras características.

O método taylorizado inviabiliza os espaços de diálogo, de discussão entre os trabalhadores, a troca de informações e de conhecimentos que permitam resolver problemas e ressignificar as normas estabelecidas, as prescrições ${ }^{14,22}$, visto que o trabalho está reduzido ao cumprimento rigoroso do que está prescrito nas regras sobre o processo na ESF.

Todavia, há que se destacar que toda atividade tem possibilidade de ser ressingularizada ou renormatizada, mesmo que parcialmente em torno de si, quando deixa de uma reprodução de sequência de atividades ou de gestos ${ }^{14-16,22}$.

Das condições de trabalho na ESF/DF, constatou-se que os trabalhadores convivem com a insuficiência de materiais considerados básicos para o desempenho das suas atividades como insumos, instrumentos, equipamentos e espaço fí- sico. Tal situação, além de gerar desgastes, pode aumentar a insegurança por parte dos trabalhadores e da população em relação aos serviços prestados. Além disso, pode ser uma fonte de desgaste cognitivo e afetivo para os trabalhadores que atuam com zelo no cuidado das famílias ${ }^{18}$.

Diversos autores afirmam que uma das possíveis justificativas para precariedade das condições de trabalho está associada à inadequação do incremento orçamentário e financeiro do financiamento da APS, havendo problemas relacionados ao montante ou à alocação dos recursos ${ }^{23-26}$.

Não obstante, o seguimento rigoroso das prescrições pode ocorrer como consequência de mecanismo de defesa originários do enfrentamento de vivências de sentimentos de impotência, mediante problemas que não são passíveis de solução por parte do trabalhador, individual ou coletivamente, devido à precarização das condições de trabalho ${ }^{10,11,12,27}$. Dejours identifica como operação padrão: a atuação do profissional exclusivamente conforme as regras ${ }^{11,13}$, confirmando que se trata de mecanismo de defesa utilizado pelos trabalhadores ao perceberem que as prescrições, se seguidas com rigor, reduzem seu desgaste.

As relações socioprofissionais nas equipes da ESF apresentam-se como a situação mais grave no contexto do trabalho. Há dificuldades na comunicação entre chefia e subordinados, falta integração no ambiente de trabalho, a comunicação entre os funcionários é frequentemente insatisfatória, bem como ocorre falta de apoio das chefias para o desenvolvimento profissional.

Tais problemas incidem negativamente no processo de trabalho em equipe, que é idealizado para o trabalho na ESF. Outros estudos realizados nas ESF de outras regiões do país mostram que as comunicações no mesmo nível hierárquico, horizontais, também são realizadas com dificuldades, o que impede a integração e a cooperação entre indivíduos e equipes, seja no compartilhamento de recursos e competências, seja na identificação de problemas e na elaboração de soluções ${ }^{17,28}$. O trabalho em equipe é afetado porque a comunicação centra-se nas relações pessoais, não nas profissionais ${ }^{22,29}$.

Essa dinâmica de gestão de pessoas com tendência à valorização da hierarquização e da centralização influencia negativamente o engajamento dos agentes, desestimulando seu envolvimento, para além do cumprimento do que é formalmente esperado. Também dificulta a cogestão do trabalho por parte do trabalhador, elemento fundamental no processo de renormatização da ati- 
vidade, de criação de valor e sentido para o trabalho ${ }^{10,16,18,22,27,30}$.

Nesse contexto, o compartilhamento de soluções que surgem na prática quotidiana vê-se prejudicado. Isso compromete o processo coletivo e individual de reelaboração das normas, das regras, o que pode vir a prejudicar a saúde do trabalhador, bem como a qualidade e a efetividade do serviço prestado à população.

Como visto, dadas as limitações das condições de trabalho, os trabalhadores da ESF/DF tendem a lançar mão de estratégias e de mecanismos de defesa que lhes possibilitem lidar com a inadequação dos meios, dos problemas com a gestão e de comunicação no processo de trabalho. Esses processos têm diferentes custos para os indivíduos e para o coletivo, conforme exposto a seguir.

Neste estudo, observou-se que o custo físico é bastante significativo, sobretudo por serem as práticas de saúde da ESF realizadas fora de edificações, extramuros. Caminhar repetidamente representa tarefa penosa. Ressalta-se que essa atividade é preponderantemente realizada pelos ACS nas visitas regulares aos domicílios sob sua responsabilidade.

No que se refere ao uso repetitivo das mãos, que se apresenta como fator que contribui para o custo físico elevado, este pode estar relacionado com a realização de atividades de forma repetida, inadequação ou insuficiência de equipamentos, entre outros.

Observou-se que o custo cognitivo foi avaliado como elevado, pois o processo de trabalho requer esforços para a superação de dificuldades que exigem o desenvolvimento de macetes, a previsão dos acontecimentos futuros, o esforço intelectual para a resolução de problemas. Esses dados sugerem que se trata de uma atividade que exige habilidades e competências complexas para solucionar questões de distintas naturezas.

O custo cognitivo advém também do uso constante da memória e da criatividade. Considerando-se o processo de trabalho na ESF em geral, que envolve atuar no ambiente onde o cidadão reside, com pouco controle por parte dos profissionais, sujeitos aos incidentes que porventura possam ocorrer, é razoável supor que este contexto exige dos profissionais competências relacionadas com a adaptação à realidade, à antecipação e à resolução de problemas.

Note-se que o custo afetivo foi avaliado como elevado, no que se refere a ser obrigado a lidar com a agressividade alheia, disfarçar os sentimentos, aparentar ter bom humor e ter controle emocional, que estão relacionadas com a tipicidade do trabalho, ou seja, a necessidade de cuidar de outros seres humanos, em situações de fragilidades, por vezes, extrema.

Reitera-se que esse contexto de trabalho, possivelmente, é marcado pela incerteza, pela ambiguidade, o que exige dos profissionais soluções não usuais, não prescritas ou mesmo desconhecidas. Caso os trabalhadores tenham mecanismos de reelaboração individual e coletiva, que permitam a ressignificação das incertezas e ambiguidades, reduzindo-as conforme as possibilidades, estes custos poderão ser reduzidos. Nesse sentido, a existência de mecanismos institucionalizados de escuta poderia potencializar as estratégias usadas pelos trabalhadores, viabilizando o processo de renormatização ${ }^{11-16,20,22,31}$.

A despeito do desgaste provocado pelo trabalho, a avaliação das vivências de prazer e sofrimento pelos trabalhadores da ESF demonstra que o trabalho tem-lhes possibilitado sentimentos de prazer intenso, que contribuem para a consolidação do de realização profissional, que se originam naquele de identificação com a tarefa que realizam, satisfação, motivação, orgulho, entre outros sentimentos positivos ${ }^{13,20,32}$.

Apesar de o trabalho em saúde trazer à consciência, de forma constante e intensa, nossa mortalidade e fragilidades diversas - em função do contato com a morte, doenças, mutilações, e da inserção em ambientes por vezes perigosos - também traz à tona uma sensação de potência, ao ter o profissional da área papel ativo na recuperação da saúde de outrem. Essa potência, este poder agir ${ }^{10,27,33}$ em relação a situações adversas e ver os resultados de suas ações no corpo do outro talvez ajude a compreender as vivências de satisfação, de bem-estar e de orgulho registradas nos resultados desta pesquisa.

Dejours aponta que a sublimação, conceito de origem psicanalítica, é um mecanismo de defesa eficaz, relacionado com a realização de atividades socialmente valorizadas. Nesse contexto, pode ser compreendido o prazer produzido pelo trabalho na atenção à saúde, no cuidado do outro $^{13,20,32}$. Esse parece ser a dominante entre os trabalhadores da ESF/DF.

Os resultados demonstram que há falta de reconhecimento e de valorização profissional, possivelmente pela instituição que os expõe a precárias condições de trabalho. Segundo Mendes "O reconhecimento é o processo de valorização do esforço e do sofrimento revertido para realização do trabalho, que possibilita ao sujeito a construção de sua identidade, traduzida afeti- 
vamente por vivência de prazer e de realização de si mesmo" 20 .

No entanto, esta falta de reconhecimento está mediada por aspectos prazerosos do trabalho na ESF, tais como a ausência de discriminação, a não ocorrência de desqualificação do trabalho realizado, a presença de liberdade de diálogo entre os colegas e as chefias, sensação de orgulho (valorização social e subjetiva) pelo trabalho realizado.

Os resultados demonstram que há solidariedade entre os trabalhadores, confiança mútua e cooperação, além de liberdade para expressaremse em relação ao trabalho. Esses aspectos são fundamentais para que os problemas encontrados na realidade da execução do trabalho, nas atividades concretas, sejam objeto de ação coletiva, contribuindo ativamente para a reelaboração e renormatização $0^{10-16,20,22,27,30,33}$, que corroborem para a produção de prazer no trabalho.

No entanto, se comparados com os resultados encontrados anteriormente, relativos à inadequação das condições de trabalho e aos elevados custos humanos, estes resultados parecem indicar que os problemas relativos à comunicação e à integração são predominantemente de natureza político-organizacional, ou seja, oriundos do nível de gestão mais macro, dos níveis hierárquicos superiores da gestão, pois em nível micro, nas unidades, os vínculos de solidariedade, de comunicação, de suporte afetivo e cognitivo existem, mas possivelmente são de tipo pessoal, informal ${ }^{28}$.

Estes resultados demonstram a possibilidade da ocorrência, em nível micro, no quotidiano das unidades, daquilo que Schwartz ${ }^{14}$ denomina de Entidades Coletivas Relativamente Pertinentes (ECRP), pois os trabalhadores apontam para a existência de uma organização informal que possibilita não somente a troca de conhecimentos e experiências por meio de canais fora da racionalidade administrativa, mas também o diálogo dos trabalhadores no quotidiano de seu trabalho, potencializando a cooperação entre os mesmos. A existência das ECRP contribui para coordenação das atividades quotidianas.

Caberia à gestão, do nível mais macro, estimular e propiciar espaços de reflexão acerca do processo de trabalho, que podem passar pela própria organização, pelas ações reais que foram efetuadas para a solução de um novo problema, ou mesmo pela reflexão subjetiva do sujeito sobre o uso que faz de si mesmo nesse contexto ${ }^{10-15,27,31,33}$.

A operacionalização quotidiana de modelos que substituam eficientemente o taylorismo é um desafio a ser enfrentado por trabalhadores, ges- tores e pesquisadores ${ }^{31}$. Uma estratégia de enfrentamento é a criação e o fortalecimento de mecanismos de cogestão do trabalho.

\section{Conclusão}

Esta pesquisa evidencia um modo de gestão do processo de trabalho taylorizado na ESF, caracterizado pela divisão de trabalho entre formuladores e executores, pela repetição das tarefas, pela fiscalização de desempenho, pela fragilidade da comunicação formal entre os diferentes níveis hierárquicos.

A esse contexto soma-se a inadequação e a insuficiência dos recursos necessários para a realização do trabalho quotidiano, que causam custos humanos, desde os físicos e os cognitivos até os afetivos, relacionados aos esforços realizados para o cuidar dos usuários no local onde residem.

Destarte as dificuldades relacionadas ao processo, no que se relaciona às vivências de prazersofrimento, apesar da manifestação de sofrimento que é sentido pelos trabalhadores na forma de estresse, frustração e insegurança, evidenciou-se que o trabalho é muito prazeroso para seus trabalhadores. Observa- se que, no interior das equipes, existe espaço profícuo para renormatização do processo pelos trabalhadores, por meio da confrontação das normas preexistentes e a realidade objetiva e subjetiva.

Todavia, há que se pensar em adoção de modelos de gestão mais democráticos, que facilitem aos trabalhadores o uso de si, passando pelo uso de si pelos outros, tendo como perspectiva a construção do que se denomina de ECRP, com capacidade para criar, sobretudo provocar mudanças que convoquem não apenas os trabalhadores, mas também os gestores para o processo de renormatização dos processos de trabalho.

\section{Colaboradores}

HE Shimizu elaborou o Projeto, orientou a coleta e a organização dos dados, e realizou a discussão final dos dados. DA Carvalho Junior coletou e organizou os dados e realizou a discussão preliminar. 


\section{Referências}

1. Mendes EV. A modelagem das redes de Atenção à Saúde [monografia]. Belo Horizonte: Secretaria de Estado de Saúde de Minas Gerais; 2007 Jul [acessado 2010 jul 05]. Disponível em: http://www. saude.es.gov.br/download/A_MODELAGEM_ DAS_REDES_DE_ATENCAO_A_SAUDE.pdf.

2. Starfield B. Atenção primária: equilíbrio entre necessidades de saúde, serviços e tecnologia. Brasília: Unesco; 2002.

3. Organização Pan Americana de Saúde (OPAS). Renovação da atenção primária em saúde nas Américas. Documento de posicionamento da Organização PanAmericana da Saúde/ OMS [Internet]. Washington, DC: OPAS; 2008 [acessado 2010 jul 05]. Disponível em: http://www.opas.org.br/servico/arquivos/Sala 5575.pdf

4. Hildebrand SM. O modelo político-tecnológico da atenção à saúde da família no Distrito Federal: 1997 a 2006 [tese]. Brasília: Universidade de Brasília; 2008.

5. Göttems LBD. Análise da política de atenção primária à saúde desenvolvida no Distrito Federal: a articulação entre o contexto político, os problemas, as alternativas e os atores na formação da política de saúde (1979 a 2009) [tese]. Brasília: Universidade de Brasília; 2010.

6. Araújo MBS, Rocha PM. Trabalho em equipe: um desafio para a consolidação da estratégia de saúde da família. Cien Saude Colet 2007; 12(2):455-464.

7. Facchini LA, Piccini RX, Tomasi E, Thumé E, Silveira DS, Siqueira FV, Rodrigues MA. Desempenho do PSF no Sul e no Nordeste do Brasil: avaliação institucional e epidemiológica da Atenção Básica à Saúde. Cien Saude Colet 2006; 11(3):669-681.

8. Lima NT, organizador. Saúde e democracia: história e perspectivas do SUS. Rio de Janeiro: Fiocruz; 2005.

9. Brasil. Ministério da Saúde (MS). Secretaria de Atenção à Saúde. Política Nacional de Atenção Básica [internet]. Brasília: MS; 2006 [acessado 2010 jul 5]. 60 p. (Série A. Normas e manuais técnicos); (Série pactos pela saúde 2006; v. 4). Disponível em: http:/ /portal.saude.gov.br/portal/arquivos/pdf/pacto volume4.pdf

10. Machado C, Santos PHF, Bento R, Nogueira ML, Dorigo N, entrevistadores. Entrevista: Yves Clot. Mosaico, Estud Psicol 2008; 2(1):65-70.

11. Dejours C. Conferências Brasileiras. São Paulo: Fundap; 1999.

12. Dejours C. Subjetividade, trabalho e ação. Producão 2004; 14(3):27-34.

13. Dejours C. A loucura do trabalho. Estudo de Psicopatologia do trabalho. São Paulo: Cortez; 2003.

14. Schwartz Y, Durrive L, organizadores. Trabalho \& Ergologia. Conversas sobre a atividade humana. Niterói (RJ): EdUFF; 2007.

15. Schwartz Y. Trabalho e saber. Trab Educ 2003; 12(1):21-34

16. Gomes L, Abrahão AL, Vieira M, entrevistadores. Entrevista: Yves Schwartz. Trab Educ Saúde 2006; 4(2):457-466.

17. Robbins SP. Fundamentos do comportamento organizacional. São Paulo: Prentice Hall Brasil; 2008.
18. Schwartz Y. A experiência é formadora? Educ Real 2010; 35(1):35-48.

19. Medronho RA, Bloch KV, Werneck GL. Epidemiologia. Rio de Janeiro: Atheneu; 2008.

20. Mendes AM. Psicodinâmica do trabalho: teoria método e pesquisas. São Paulo: Casa do Psicólogo; 2007.

21. Brasil. Ministério da Saúde (MS). Conselho Nacional de Saúde. Resolução no. 196/1996. Diretrizes e Normas Regulamentadoras de Pesquisas Envolvendo Seres Humanos. Diário Oficial da União 1996; out 10.

22. Santos-Filho SB, Barros, MEB, organizadores. Trabalhador da saúde. Muito prazer! Protagonismo dos trabalhadores na gestão do trabalho em saúde. Ijuí (RS): Unijuí; 2009.

23. Organização Pan-Americana da Saúde (OPAS), Organização Mundial da Saúde. Ministério da Saúde do Brasil. Experiências e desafios da atenção básica e saúde familiar: caso Brasil. Brasília: OPAS; 2004. (Série Técnica Projeto de Desenvolvimento de Sistemas e Serviços de Saúde; 8)

24. Sousa MF, Hamann EM. Programa Saúde da Família no Brasil: uma agenda incompleta? Cien Saude Colet 2009; 14(Supl. 1):1325-1335.

25. Solla JJSP, Reis AAC, Soter APM, Fernandes AS, Palma JJL. Mudanças recentes no financiamento federal do Sistema Único de Saúde: atenção básica à saúde. Rev Bras Saude Matern Infant 2007; 7(4):495502.

26. Castro ALB, Machado CV. A política de atenção primária à saúde no Brasil: notas sobre a regulação e o financiamento federal. Cad Saude Publica 2010; 26(4):693-705.

27. Soares DHP, Coutinho MC, Nardi HC, Sato L, entrevistadores. Entrevista: Yves Clot. Cad Psicol Soc Trab. 2006; 9(2):99-107.

28. Levy E, Drago PA, organizadores. Gestão pública no Brasil contemporâneo. São Paulo: FUNDAP; 2005.

29. Kell MCG, Shimizu HE. Existe trabalho em equipe no Programa Saúde da Família? Cien Saude Colet 2010; 15(Supl. 1):1533-1541.

30. Durrive L, Schwartz Y. Glossário da ergologia. Laboreal [site na Internet]. 2008 [acessado 2011 jan 20]; 4(1):23-28. Disponível em: http://laboreal.up. pt/media/artigos/166/23-28pt.pdf

31. Campos GWS. O anti-Taylor: sobre a invenção de um método para co-governar instituições de saúde produzindo liberdade e compromisso. Cad Saude Publica 1998; 14(4):863-870.

32. Merlo RC. Psicodinâmica do trabalho. In: Jacques MG, Codo W, organizadores. Saúde mental \& trabalho. Leituras. Petrópolis: Vozes; 2002. p. 130-142.

33. Clot Y. A função psicológica do trabalho. Petrópolis: Ed. Vozes; 2006.

Artigo apresentado em 02/05/2011

Aprovado em 08/06/2011

Versão final apresentada em 15/06/2011 